\title{
Characterisation of foliated rock masses using implicit modelling to guide geotechnical domaining and slope design
}

\author{
E Saunders SRK Consulting (Canada) Inc., Canada \\ A LeRiche SRK Consulting (Canada) Inc., Canada \\ T Shapka-Fels SRK Consulting (Canada) Inc., Canada \\ W Barnett SRK Consulting (Canada) Inc., Canada
}

\begin{abstract}
The stability of rock slopes designed and excavated within anisotropic rock masses are influenced by several factors, some of which include spacing intensity, continuity, roughness, dip and dip direction, and waviness. Foliation-parallel instabilities are often expressed at the multi-bench or inter-ramp scale due to the high persistence, larger-scale dilation and breaking of intact rock bridges. Functional pit slope designs need to account for the variability in foliation character with consideration to the mining geometries being developed.

The accepted approach is to partition the rock mass into three-dimensional (3D) geotechnical domains to reduce complexity for slope design guidelines. Inputs guiding the development of the geotechnical domains can either be from highly manual interpretations, which are tedious and coarse in resolution, or implicit 3D foliation modelling methods. To demonstrate this, implicit models, such as form interpolants and/or block models, were first used at Jwaneng mine and have subsequently been generated and used to inform domaining and design at two operating mines (Rainy River and Rosebel Gold mines) and one other project site. The models were developed from different sources of geotechnical/geological data (i.e. oriented drillhole logging, televiewer, grade cutoff, pit face and photogrammetry mapping). The validation of the models has been further investigated with techniques presented in this paper.
\end{abstract}

Keywords: rock mass fabric, kinematics, geotechnical risk, pit design, bench performance, implicit modelling

\section{Introduction}

With the increasing ability to model geotechnical stability conditions in 3D comes the importance of spatially characterising rock mass variability. This is particularly significant in deposits in highly anisotropic rock, which influences everything from bench-scale to overall pit slope performance. Currently, accepted 2D modelling approaches often can't adequately represent the complex 3D rock mass behaviour, which leads to model results which don't capture the likely mechanics of failure.

The purpose of this paper is to demonstrate the use of 3D implicit modelling techniques in several case studies of geological deposits containing pervasive rock mass fabric. The results of the interpolant modelling have been used in each case to inform geotechnical domaining for technical study or operational design, in a manner that avoids the confined 2D analysis typical of design sections.

\section{Rock mass anisotropy}

\subsection{Geological setting}

Rock anisotropy is caused by pervasive fabric within a rock mass such as foliation, bedding, vein systems or fractures. The development of such anisotropy is therefore, related to the geological setting and the tectonic deformation history (Hencher et al. 2011). 
The observed characteristics can be categorised into the following fundamental rock types:

- Foliated metamorphic rocks: including phyllites, slates, schists and some schistose gneisses. The temperature and pressure conditions contribute to the development of preferred orientations of crystalline minerals and platy micas (Passchier \& Trouw 2005) and commonly associated structural folding. The intensity of anisotropy is related to the intensity of strain, the rock type and the metamorphic grade. In special cases, the metamorphism can lead to the formation of weak mineral layering such as talc.

- Stratified sedimentary rocks: including mudstones, siltstones, sandstones and limestones. Bedding and lamination anisotropy in these rocks is related to the temporal and spatial alignment of similar grain sizes at the time of deposition. The precipitation/cementation processes related to carbonate and chemically derived rocks can exhibit anisotropy, however, may be less obvious than clastic rocks. Banded iron formations (BIF) may be classed as both stratified and slightly metamorphosed due to the subjected low temperature/pressure grades.

- Igneous/volcanic rocks: that exhibit flow structures, such as sheet or exfoliation joints and volcanic layering, however, generally is less common for the development of pervasive fabric. In some cases, intense parallel fracture systems develop in spatial association with fault zones. If the fractures are continuous, they can also be regarded as a rock anisotropy.

It is important to return to geological fundamentals to understand possible anisotropy characteristics. Figure 1 provides a schematic for the development of metamorphic rock types and associated fabric development.

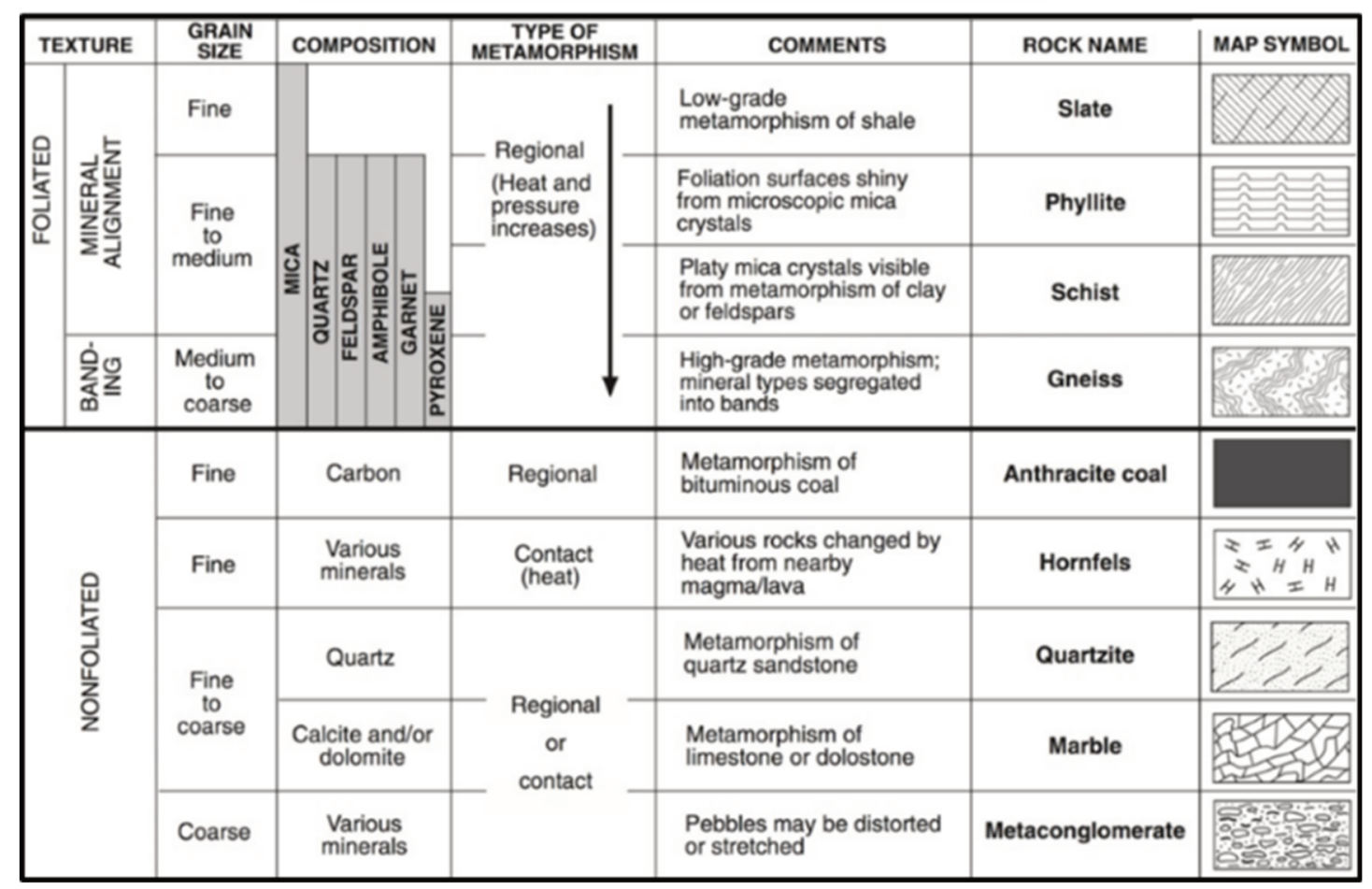

Figure 1 Schematic of degree of metamorphism and associated mineral assemblage and fabric character (The University of the State of New York 2011)

\subsection{Tectonic deformation}

Phases of tectonic deformation can overprint a primary rock mass fabric following the initial geological formation. The deformation may contribute to the metamorphic development of a new generally pervasive foliation, commonly associated with folding, and/or may lead to the formation of high strain, structurally deformed zones. Structurally deformed rocks can be represented by both pervasive brittle or ductile planar 
anisotropic deformation textures. High strain shear zones contain planar mylonitic fabrics or S-C foliation. In some brittle fault systems, damage zones may contain parallel faults, fractures and/or veins that form from locally high deviatoric stress and/or fluid over-pressurisation.

Structural deformation also causes changes in orientation of pre-existing fabrics. Folding rotates the orientation of the foliation, therefore requiring an understanding of the fold patterns. Faulting disrupts and rotates pre-existing fabrics. For example, it is common for sedimentary sequences to be offset by normal and thrust faults with bedding orientations different between the fault blocks, such as those observed in the coal measure formations in British Columbia, Canada. Figure 2 shows a cross-section through fault blocks with bedding dips represented by the coal seam model.

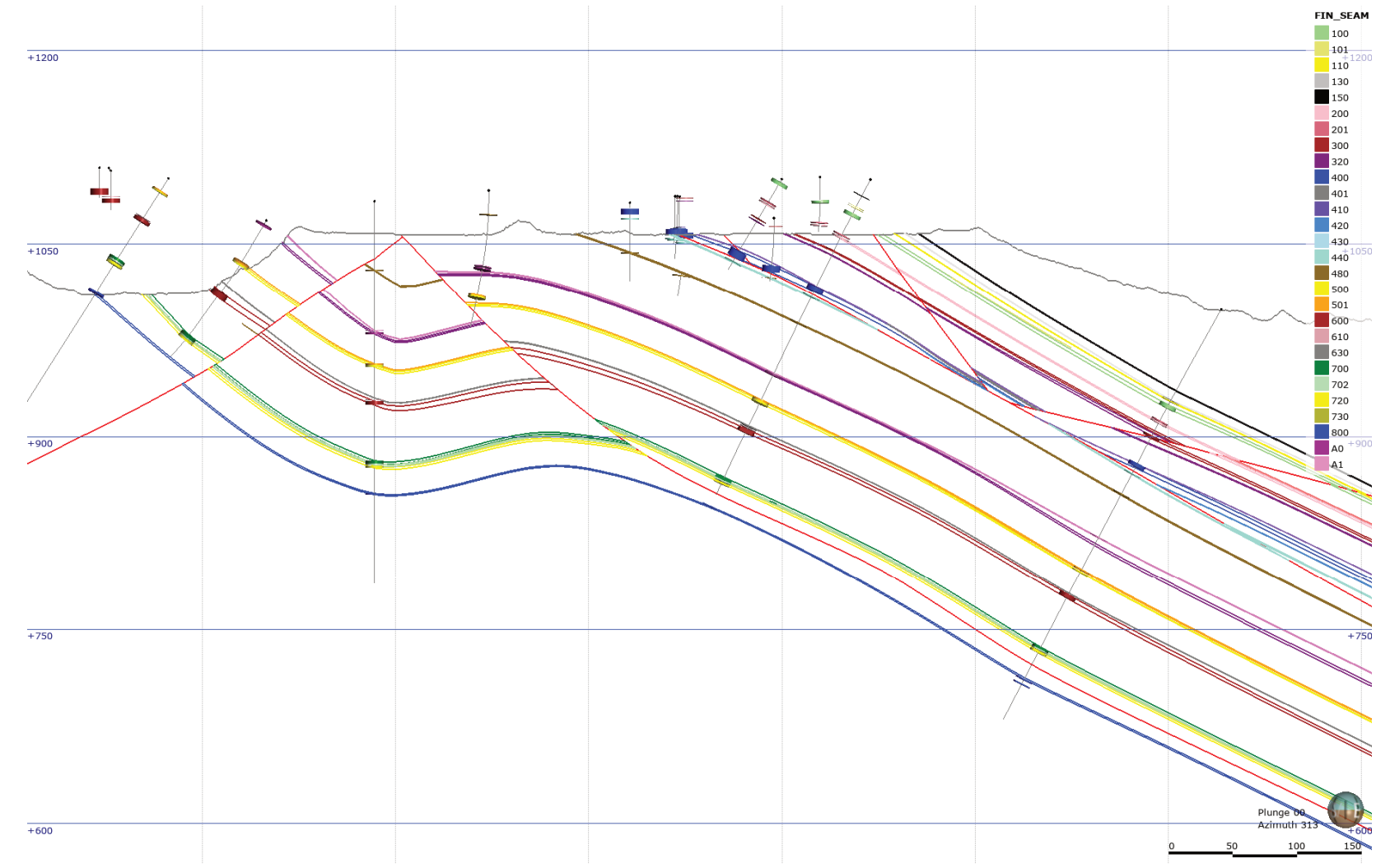

Figure 2 Orientation of stratified coal measures sequences offset by fault blocks

\subsection{Failure mechanisms}

Within the open pit context, the slope stability behaviour may be controlled by the following characteristics of the anisotropic rock fabric:

- Type: the geological origin influences the nature of the anisotropic fabric with respect to waviness, roughness, fracture intensity and surface condition. The nature of anisotropic fabric may change from one domain, or design sector, to the next.

- Orientation: the local and deposit-wide variability and direction of shear strength weakening with respect to the planned or exposed slope face aspects.

- Continuity: the trace length of the geological fabric can have an influence on slope design depending on the continuity of the features and associated rock bridges.

- Spacing and/or intensity: the degree of bedding spacing or foliation intensity with respect to slope height influences susceptibility to sliding where exposed in the slope face. 
Pit slope design must, therefore, consider these characteristics when assessing potential failure mechanisms at various scales. In anisotropic rock, geotechnical stability can be related to the following fundamental failure mechanisms (Figure 3):

- Planar sliding or toppling along the anisotropic rock fabric.

- Deformation through the rock mass, by shearing and dilation of the pervasive rock fabric.

- Combination of discrete structures and rock mass anisotropy deformation.

These failure mechanisms can be further aggravated because of the presence of low strength, highly jointed, rocks rich in clay minerals (Stead \& Wolter 2015).
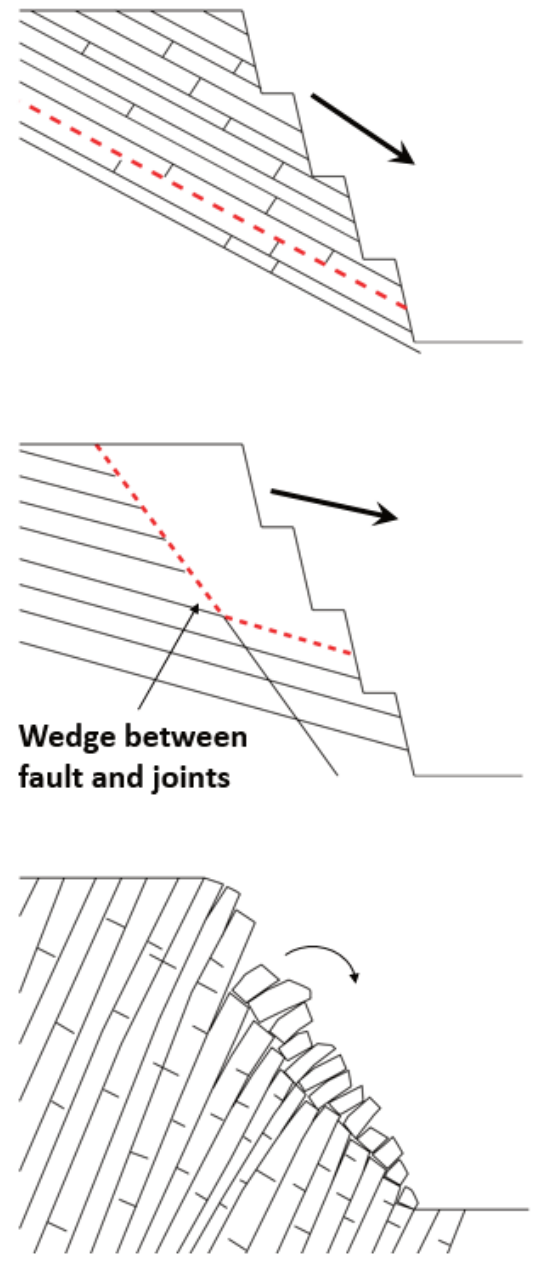
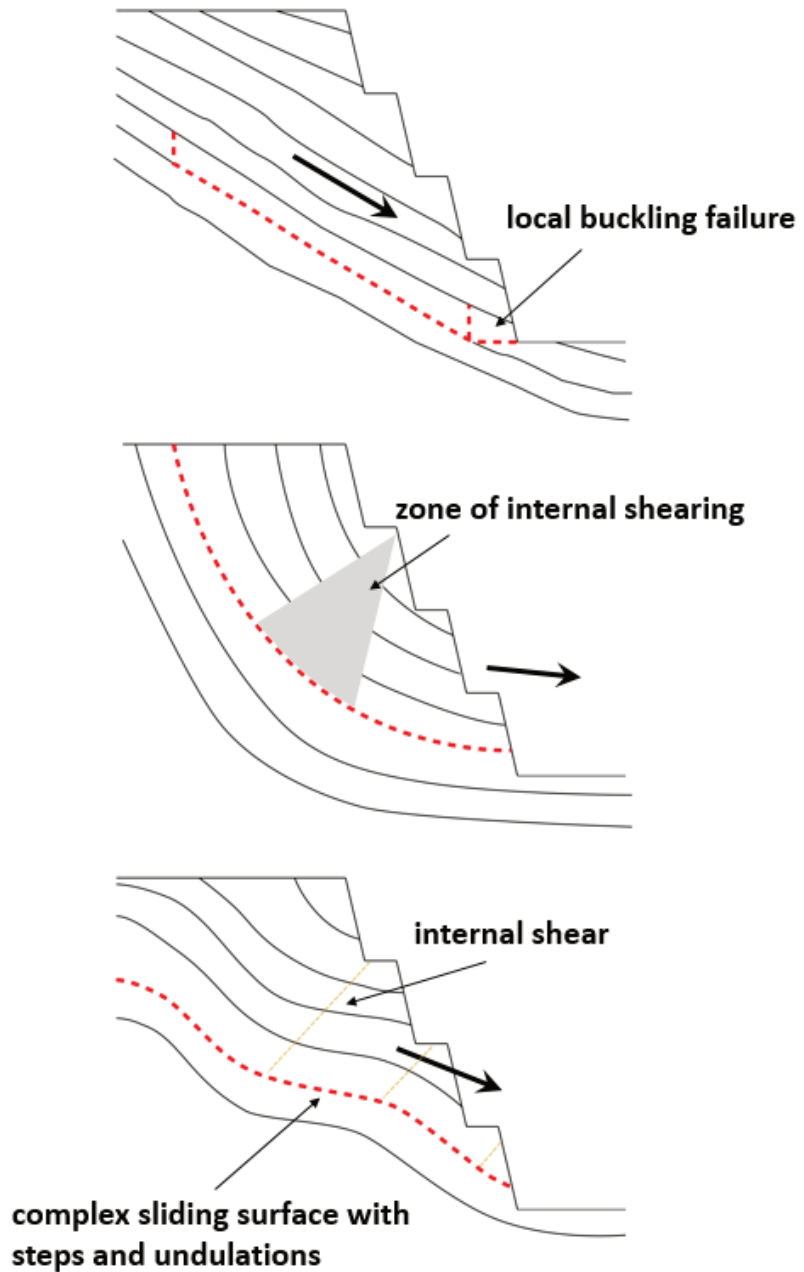

Figure 3 Classification of pit slope failure mechanisms related to anisotropic rock mass conditions (after Stead \& Wolter 2015)

\section{$3 \quad 3 D$ fabric modelling}

\subsection{Implicit modelling}

Conventionally, geological features can be modelled through manual digitization processes of data points interpreted by the user. This process typically results in a biased and possibly overly linear interpretation. Although tools exist to make the explicit modelling process more efficient, it still is essentially a highly interpretative process, rather than one guided by mathematical logic.

With ongoing advances in computer processing ability, use of well-developed implicit modelling techniques has become more viable for geological modelling. This allows for the incorporation of large amounts of data 
from various sources such as core orientation, televiewers and pit wall mapping, with more data-rich sources such as LiDAR mapping or geophysical surveys. Although the computation of the model is founded in mathematical algorithms, the user is able to define constraints to the model such as general structural trends, cross-cutting relationships, or more detailed observations such as fold wavelength and amplitude. A resulting 3D form interpolant model can be created as a continuous surface between each data point, with the interpolation based on the user-defined conditions or the interpolants can simply model the trends of anisotropic fabric data, without specifically connecting spatially to the data points.

The geological complexity within geotechnical design domains influences the nature of the form interpolants that need to be created. In many cases, the anisotropic rock is folded and the wavelength and amplitude of the folds need to be appropriately simulated or accounted for in the design. In the case of tight folding (short wavelengths), the density of data would have to be high to be able to create a representative model (Figure 4). In addition, many folds have parasitic folds on the limbs (Figure 4 insert), with the amplitude and wavelength of these impacting the rock mass shear strength and overall behaviour (Zorzi et al. 2014).

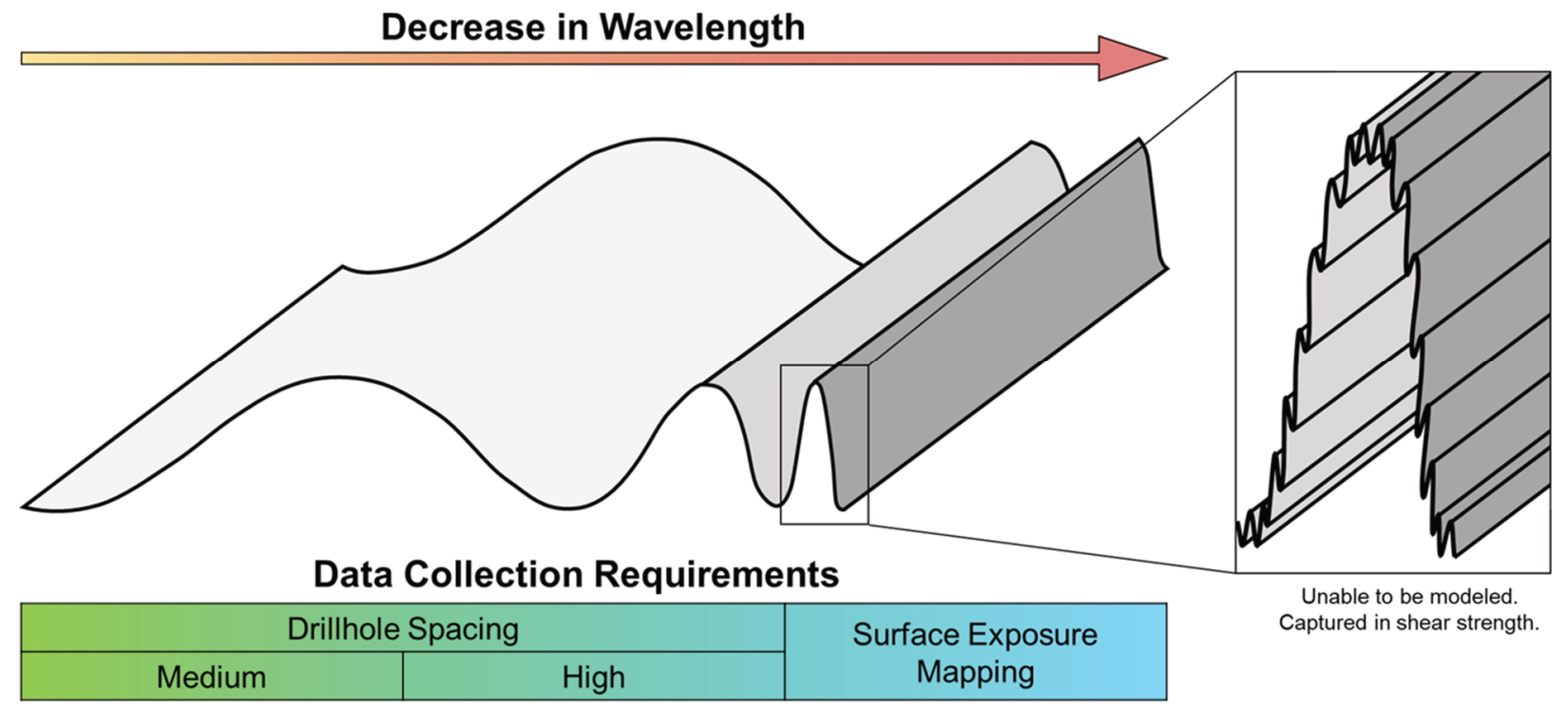

Figure 4 The quantity and spatial frequency of data required for an appropriate interpolated surface is dependent on the geological complexity, including fold wavelength (after Stead \& Wolter 2015)

\subsection{Model objective}

A reliable 3D form interpolant can support evaluation of:

- Kinematic stability interactions for design studies or for optimisation of operating slopes, at bench, inter-ramp or overall slope scale.

- Anisotropic inputs into 2D and 3D numerical model stability analyses using commercially available software.

- 3D form surfaces enable the engineers to expand beyond design section analysis, and rather evaluate the true 3D geometries. As discussed by Sainsbury \& Sainsbury (2013), there are case studies that show limitations in $2 \mathrm{D}$ stability analyses where the rock mass is highly anisotropic and cannot be adequately represented in plane strain.

The importance of 3D visualisation to practically inform engineering judgement for time-dependant mining decisions cannot be understated. As an example, Creus et al. (2019) describe the rock foliation complexity in the slope domains at Venetia mine and apply geostatistical interpolation of the orientation data to build a block model of foliation orientation and pit slope orientations. They identify planar sliding risks by applying geometric computations to the block model based on the orientations of the slopes, to output risk heat maps for the pits. 


\subsection{Methodology}

\subsubsection{Data acquisition}

A benefit of implicit modelling is the ability to quickly update the model based on the ongoing collection of data. Like any modelling exercise, the resulting output is only as good as the quality and spatial distribution of the input data.

Form interpolants require wide spatial data coverage and density across the deposit, and importantly, behind the pit walls. The implicit model should be refined with additional data collection as a project advances or bench faces are exposed. A summary of data sources is presented in Table 1. Figure 4 illustrates the need to carefully consider the required data density as a function geological complexity.

Table 1 Summary of some possible data sources for 3D form interpolant

\begin{tabular}{lll}
\hline Data source & Data collected & Validation type \\
\hline Oriented core & Alpha and beta measurements & Direct \\
Televiewer & Dip and dip direction & Direct \\
Surface mapping & Dip and dip direction & Direct \\
Lithology model & Lithology contacts, trends & Geologic \\
Brittle-structural model & Fault contact, blocks & Geologic \\
Alteration model and intensity & Alteration solids & Geologic \\
Grade shells & Grade cutoff solids & Indirect \\
Bench blasting performance & Performance evaluation related to structure & Indirect \\
\hline
\end{tabular}

Although not a direct input into 3D anisotropy models, additional data such as surface roughness and waviness, spacing/intensity, and infill/alteration properties are important for characterising the properties of the surfaces. This data needs to be captured during geotechnical logging programs. The application of the data in the model may need to include adjustments to the properties based on stress or blasting damage in active mines.

\subsubsection{Data processing}

Quality data collection is paramount to the accuracy of the 3D form surfaces, and quality assurance review is required to understand the nature of the data and apply appropriate filters. Validating large data sets can be difficult and there can be a need to prioritise certain datasets with higher confidence (e.g. surface mapping data is likely more reliable than core orientation). Filtering stereonet data can eliminate outliers or local variations that may not be representative of the overall trends. However, data processing should be completed with care not to eliminate true variation in orientation and should be assessed at an appropriate scale as defined by the geotechnical model and project objectives.

In our case studies, we apply the Leapfrog $\mathrm{GeO}^{\mathrm{TM}}$ (Seequent 2019) implicit form interpolant tool to derive the surfaces that are representative of the trends of geological anisotropic fabrics or mesh interpolants to model specific anisotropic features. It is important to understand that any implicit interpolant has mathematical controlling parameters that can be adjusted to get different results. The parameters are typically manipulated to obtain more geologically reasonable products, and like explicit modelling, the product quality is dependent on the user's geological and software skills.

The form interpolant tool in Leapfrog $\mathrm{Geo}^{\mathrm{TM}}$ applies a modified radial basis function to create surfaces from orientation data (azimuth and dip). The surface created is almost entirely influenced by the nearest data points. Away from a cloud of data points, the form surfaces will take on the orientation of the nearest single 
data point to the surface, which may be very poorly representative of the domain. The data should, therefore, be carefully spatially managed to remove or limit the influence of unrepresentative data. If data points are too closely clustered, then the software may choose to ignore all or most of the clustered data.

The problems of tight clustering of data and/or poor representation of data throughout a domain can be managed using a statistical estimation process prior to applying a form interpolant. Declustering algorithms may help in certain areas, but parts of domains devoid of data may still need to be filled with representative artificial 'averaged' orientation data to ensure no unrepresentative orientations form in volumes far from real data. Block model estimation techniques like inverse distance and kriging estimation can be used but interpolating azimuthal data (with dip and dip direction) is complex. By ensuring that the analysis includes only one structural set that is well clustered in orientation, and then appropriately dealing with azimuthal data polarity (dips either side of 0 or 90 degrees), reasonably representative results can be achieved. The result must always be verified.

\subsubsection{Validation}

Model validation can be categorised into the following: direct structure measurement, geological data comparison and indirect observation. These validation techniques are summarised in Table 2. Each of these validation techniques can inform the decision to include 'control points' which is often required to define a rule-based implicit model.

Table 2 Model validation techniques

\begin{tabular}{|c|c|}
\hline Validation type & Description \\
\hline Direct measurement & Structural orientation measure from drillhole or surface data collection \\
\hline Geological data comparison & $\begin{array}{l}\text { Comparable observations from the geological model such as surface } \\
\text { lineaments, folding, stratigraphic layering, preferential alteration and } \\
\text { lithology contacts }\end{array}$ \\
\hline Indirect observation & $\begin{array}{l}\text { Non-structural or geological observation such as comparison against the } \\
\text { grade cut-off solids, downhole assay trends and blasting performance }\end{array}$ \\
\hline
\end{tabular}

A schematic figure demonstrating the accuracy and validation of a form interpolant model is presented in Figure 5. Figure 5(a) demonstrates a reasonably reliable 3D model (blue lines = local foliation interpolant) based on closely spaced drillhole data as shown in comparison to a hypothetical 'true' foliation (grey lines). Figure 5(b) shows the change in the implicit interpretation resulting from the removal of one of these drillholes (creating a wider data spacing). Given the local waviness of this example, data density needs to be high. 


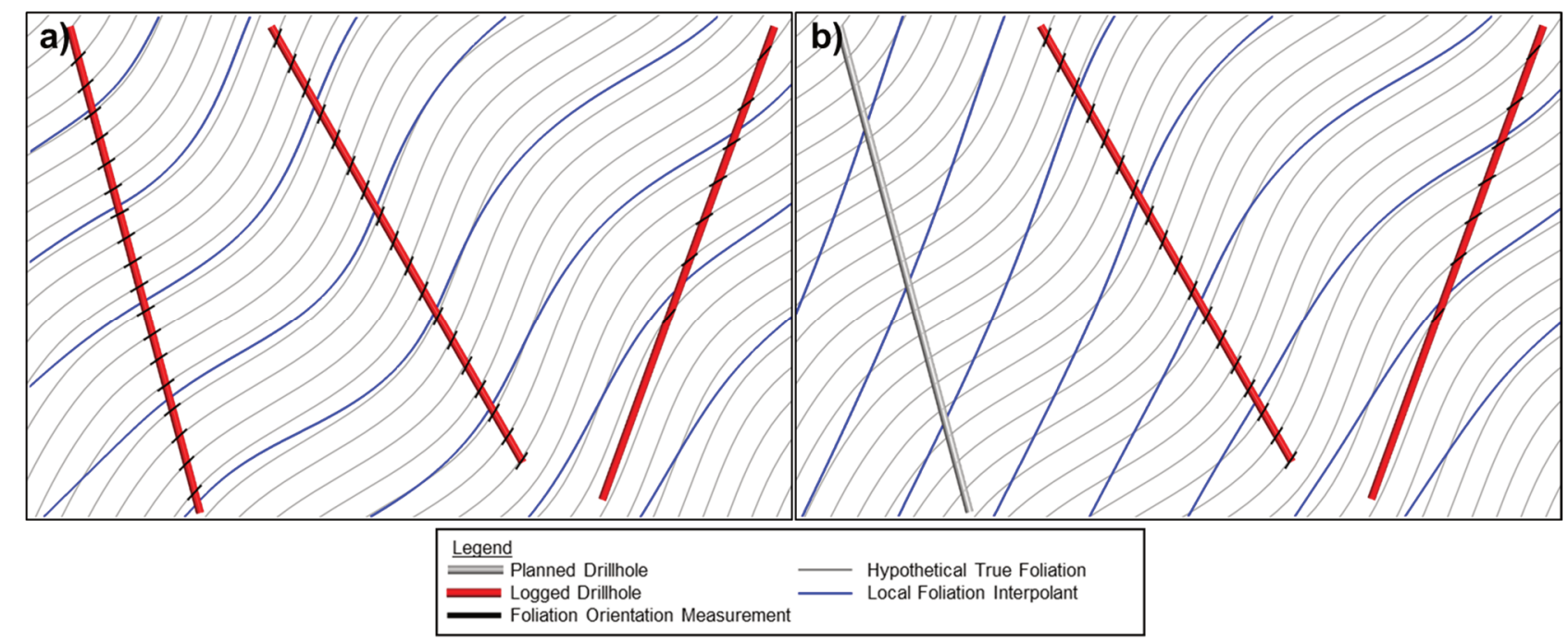

Figure 5 Example of a 2D form interpolant based on borehole data from; (a) Three evenly spaced boreholes; (b) Two closely spaced boreholes

\subsubsection{Case studies}

Three case studies have been selected that demonstrate the use of 3D fabric models to inform stability analyses and slope design decisions. In each case, the nature of the deposit and associated rock mass fabric, in addition to the quantity and spatial distribution of the data, required unique consideration when developing and validating the models.

\subsubsection{Rainy River Mine, Ontario, Canada}

Rainy River is a volcanogenic-style gold mine in Northern Ontario, Canada. The bench slopes along the north pit walls are defined by orientation of the pervasive foliation fabric related to the ductile deformation. To support the pit design, all valid foliation-parallel joint orientation data was compiled in Leapfrog Geo $^{\circledR}$ for use in generation of a 3D foliation fabric model. The data was further validated to remove outliers that were considered to have a higher localised variability and was not representative of the pit scale foliation trends. The 3D foliation model was created using a form interpolant and comprises series of meshes spaced at a resolution needed to inform the design (Figure 6).

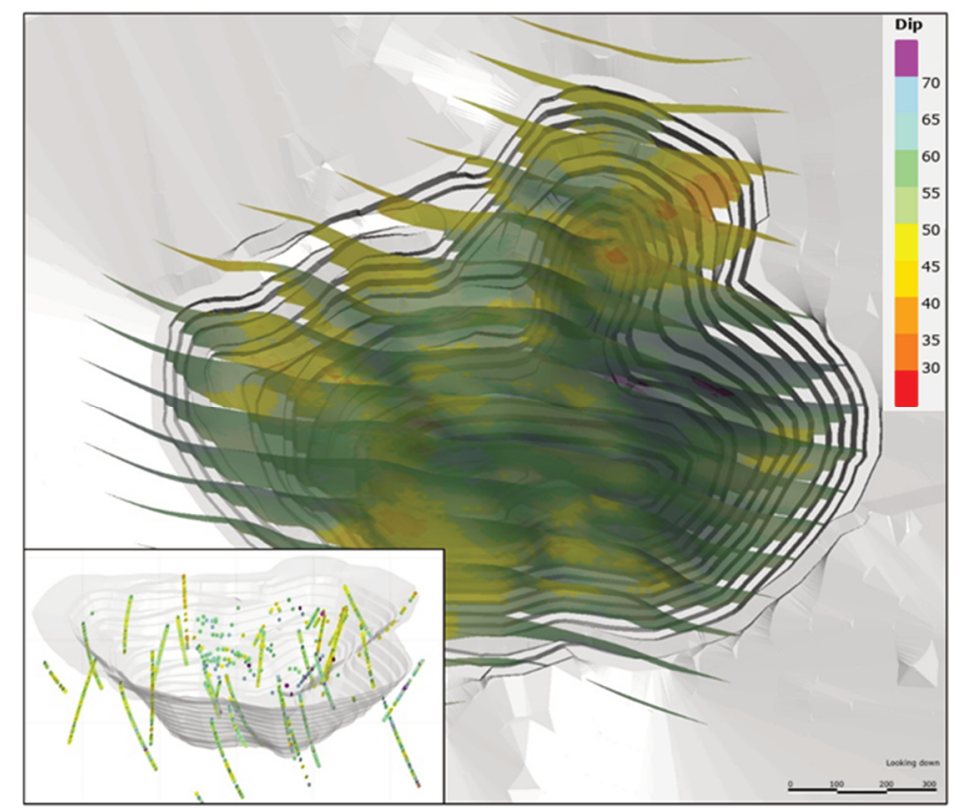

Figure 6 3D foliation model for Rainy River mine (Inset: spatial distribution of the data used in model) 
The foliation interpolant was validated by comparing cross-sections through the drillhole orientation data and the generated surface, as shown in Figure 7. An advantage at Rainy River was the exposure of bench slopes during the interim pit excavation. This allowed direct structure measurements using a field mapping and digital mapping from a laser scan to constrain the upper form interpolant surface (Figure 8).

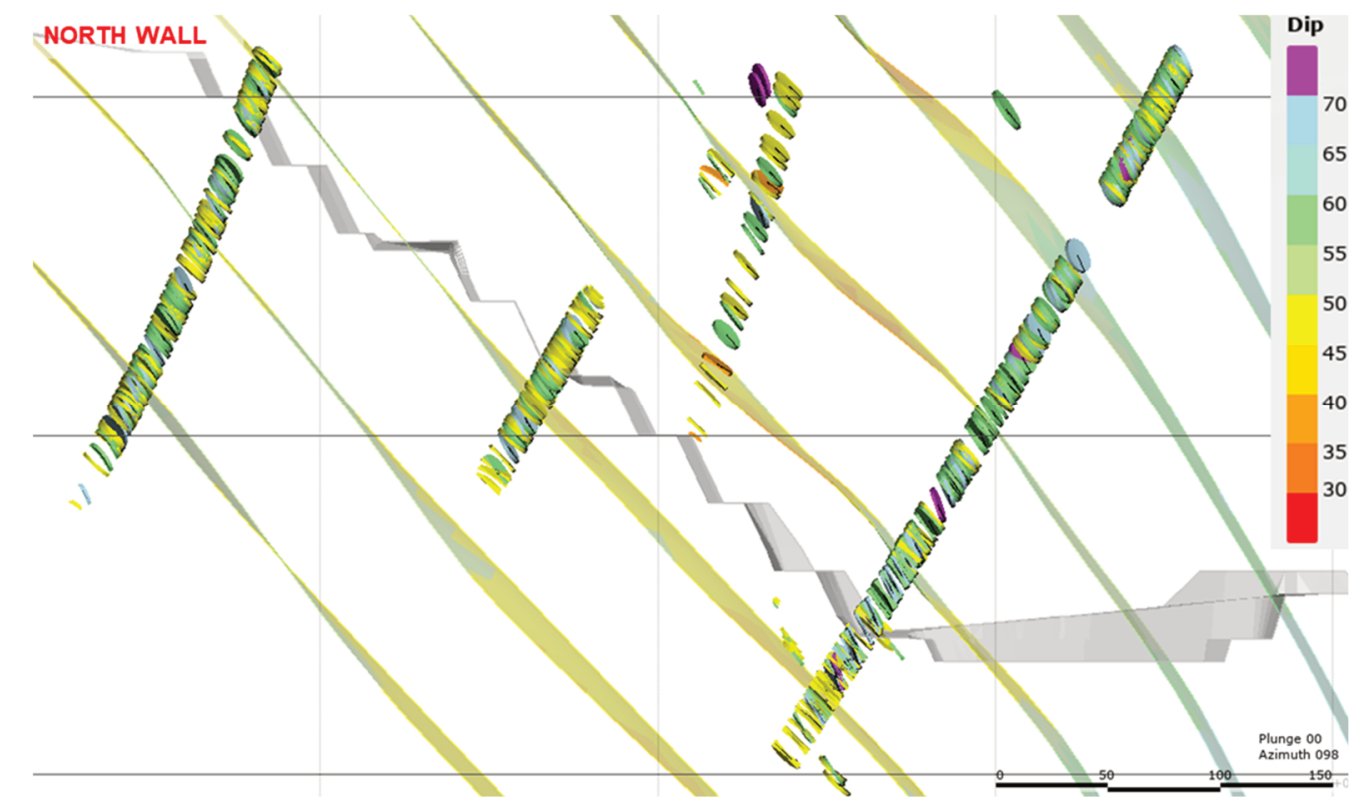

Figure 7 3D foliation model compared to the planned north wall and the foliation-parallel joint measurements

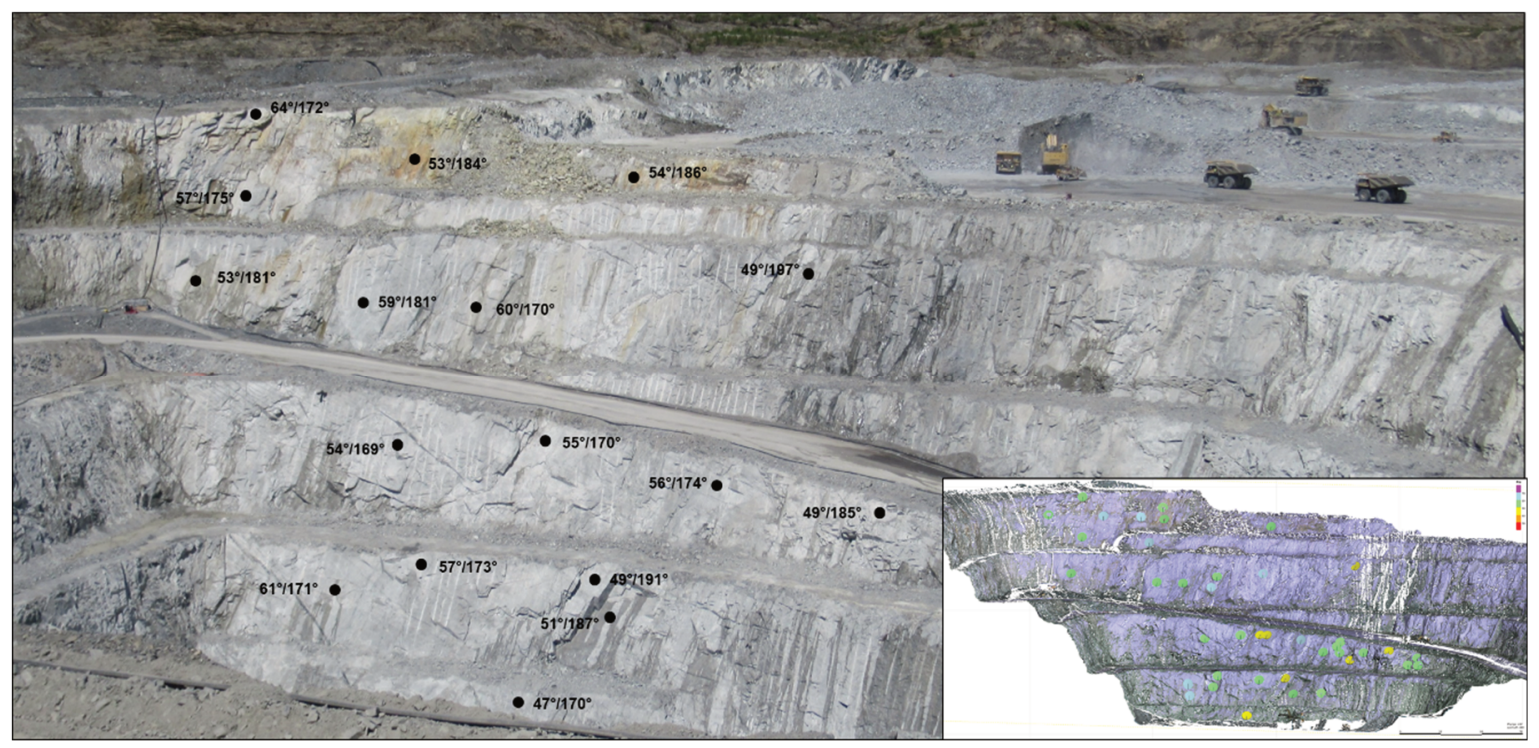

Figure 8 Data collected from a laser scan used to generate and validate the 3D foliation fabric model

The general orientation of the grade cutoff solids provided a secondary validation of the model. Variability in the foliation orientation is expected with depth and an observation-based bench design along the north walls will be adopted and guided by a continually refined 3D model.

\subsubsection{Project A, Northern Canada}

Project $A$ is a proposed open pit volcanic massive sulphide deposit located in North America. The deposit is highly foliated with two generations of fabric (S1/SO). Talc alteration occurs in continuous to semi-continuous bands parallel to the predominant foliation orientation (Figure 9). The talc layering is identified as weakness planes in the bench-scale and overall slope design. The talc zoning was implicitly modelled, which produced a better geologic representation of the talc horizons with more lateral continuity and reasonable termination 
distances from the last known drillhole intercept (Figure 10). As a result, nine layers of talc zones were created within the quartz mica packages. These often occur stratigraphically below or around an ore horizon.

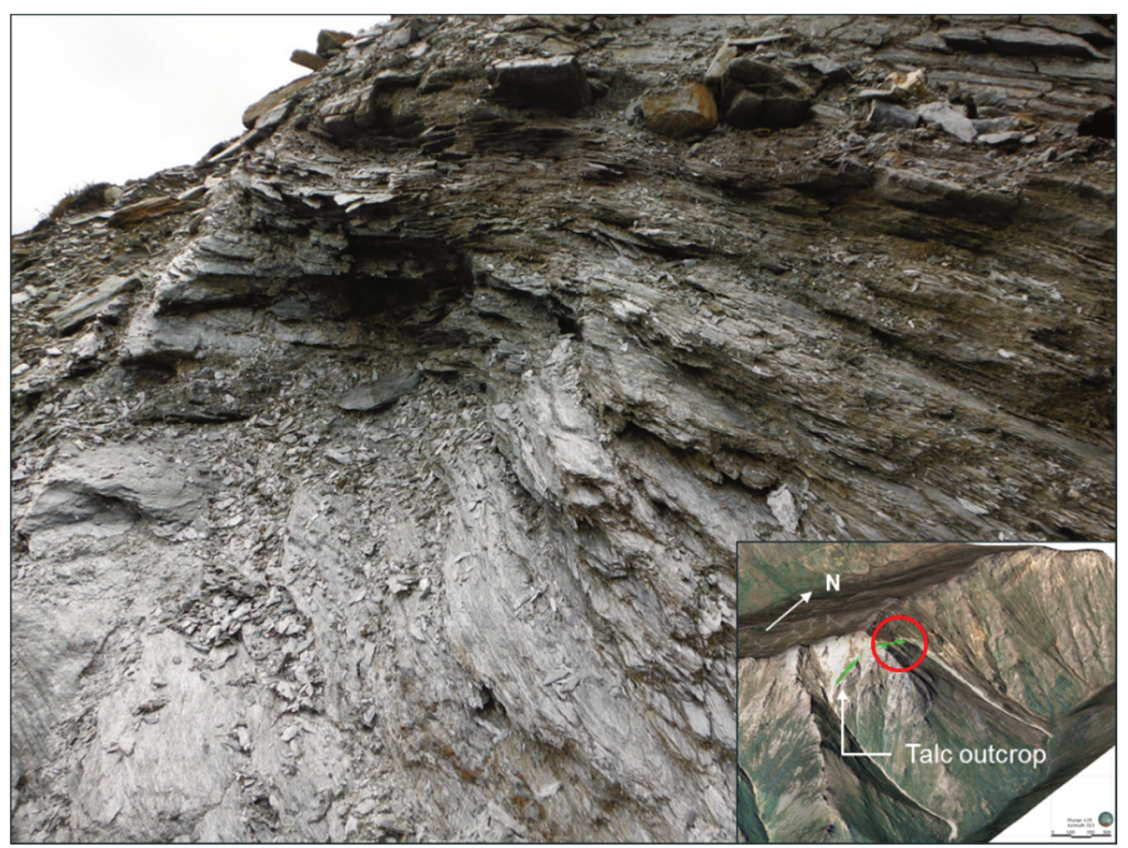

Figure 9 Foliation-parallel talc layers considered a slope risk for footwall design at Project A

To support the overall domaining, the dip direction of the S1/SO fabric was separated into a characteristic Upper and lower domain as shown in Figure 10. The design footwalls crossed both domains and adjustments were made based on the local interpolant orientation.

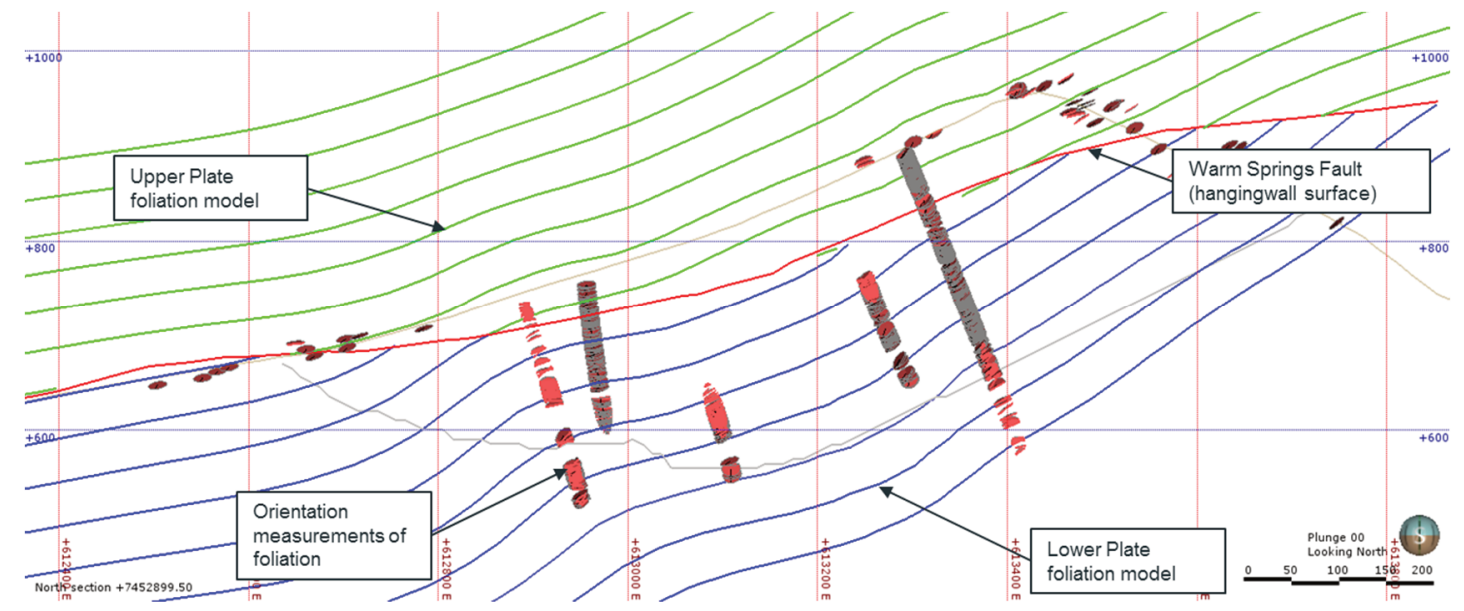

Figure 10 Upper and lower domain characterisation for Project A

\subsubsection{Rosebel Gold Mine, Suriname}

The Rosebel gold mine is an operating gold mine located in Suriname. Foliation fabric is oriented parallel to fault-hosted mineralisation, and in most cases, is sub-vertical to steeply dipping. The foliation can potentially contribute to toppling risks that need consideration for bench to inter-ramp design and implementation. This is particularly important in the weakly metamorphosed and fissile mudstones which daylight throughout the south pit wall. A form interpolant was generated for the Pay Caro Pit using core and televiewer orientations, digital mapping from laser scans and scan-line mapping (Figure 11). The data was de-clustered to assign priority to the face mapping and ATV structural data prior to evaluating the form interpolant. 


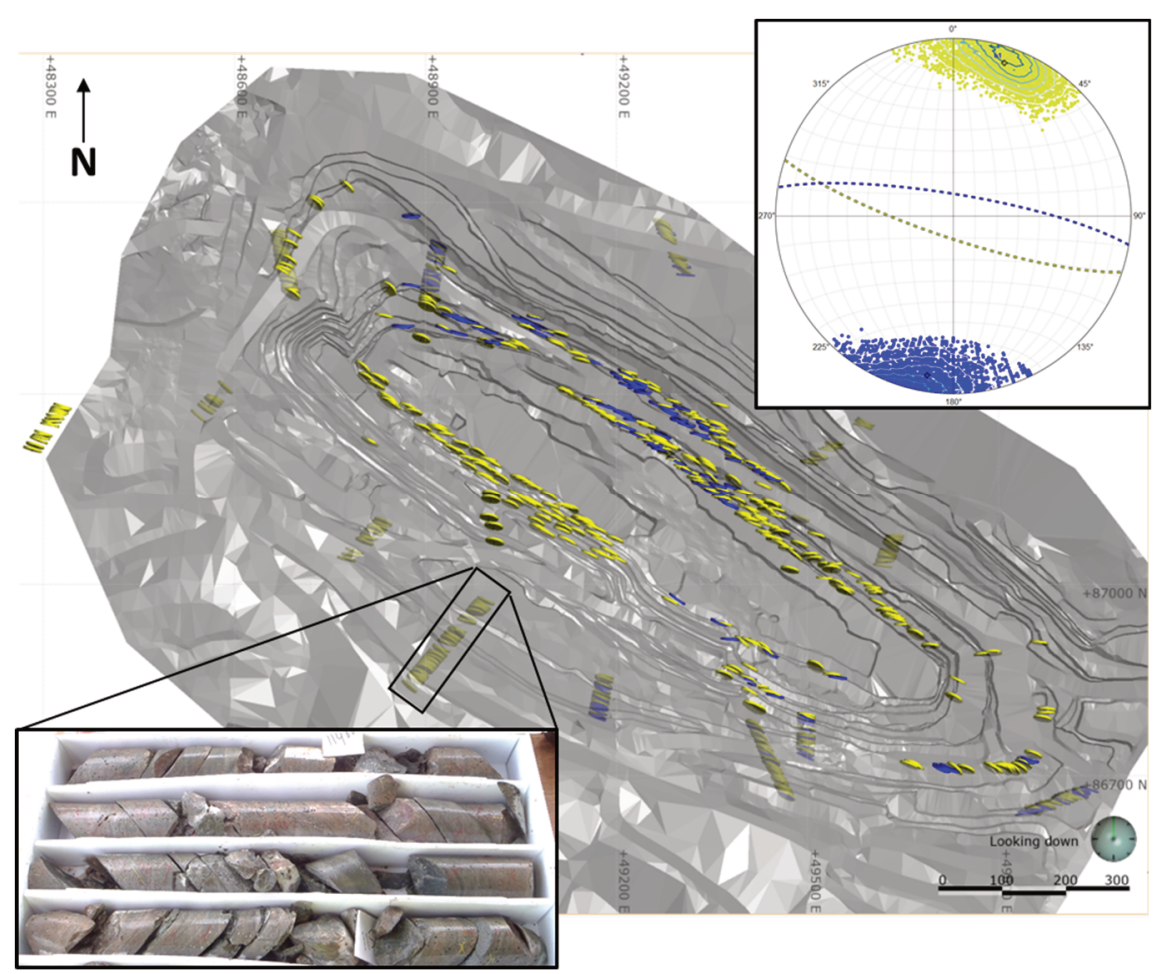

Figure 11 Foliation measurements and 3D form interpolant for the Pay Caro Pit (Inset: core photo of rock mass fabric encountered in south wall)

Although the model highlights where the foliation dips into (i.e. toppling) or out of the slope face (i.e. planar sliding), the form surfaces cannot explicitly identify possible stability risks (i.e. in areas of fissile mudstone intervals). A geotechnical block model was developed to evaluate the potential risk of toppling failure. This followed the general process of:

1. Assign each block within the model a local dip and dip direction based on the closest triangulated pit mesh.

2. Exclude any blocks which are sub-horizontal (i.e. benches, ramps, pre-mining topography).

3. Evaluate the foliation interpolant onto the block model by assigning each valid block (from Step 2) a dip and dip direction of the nearest portion of the form interpolant.

4. Compare the difference in dip/dip direction of the pit with the foliation model for each block.

5. If the criteria for toppling is met, colour the block based on likelihood of kinematic instability.

The result of this approach and the foliation interpolant is shown in Figure 12. Toppling risks are shown to be more prevalent in the south wall, where foliation measurements are mostly dipping back into the pit wall (Figure 11) and where the pit intersects intervals of mudstone. This approach can be used to inform operational risk and provide input to design changes based on the likelihood of toppling through discrete mudstone units. 


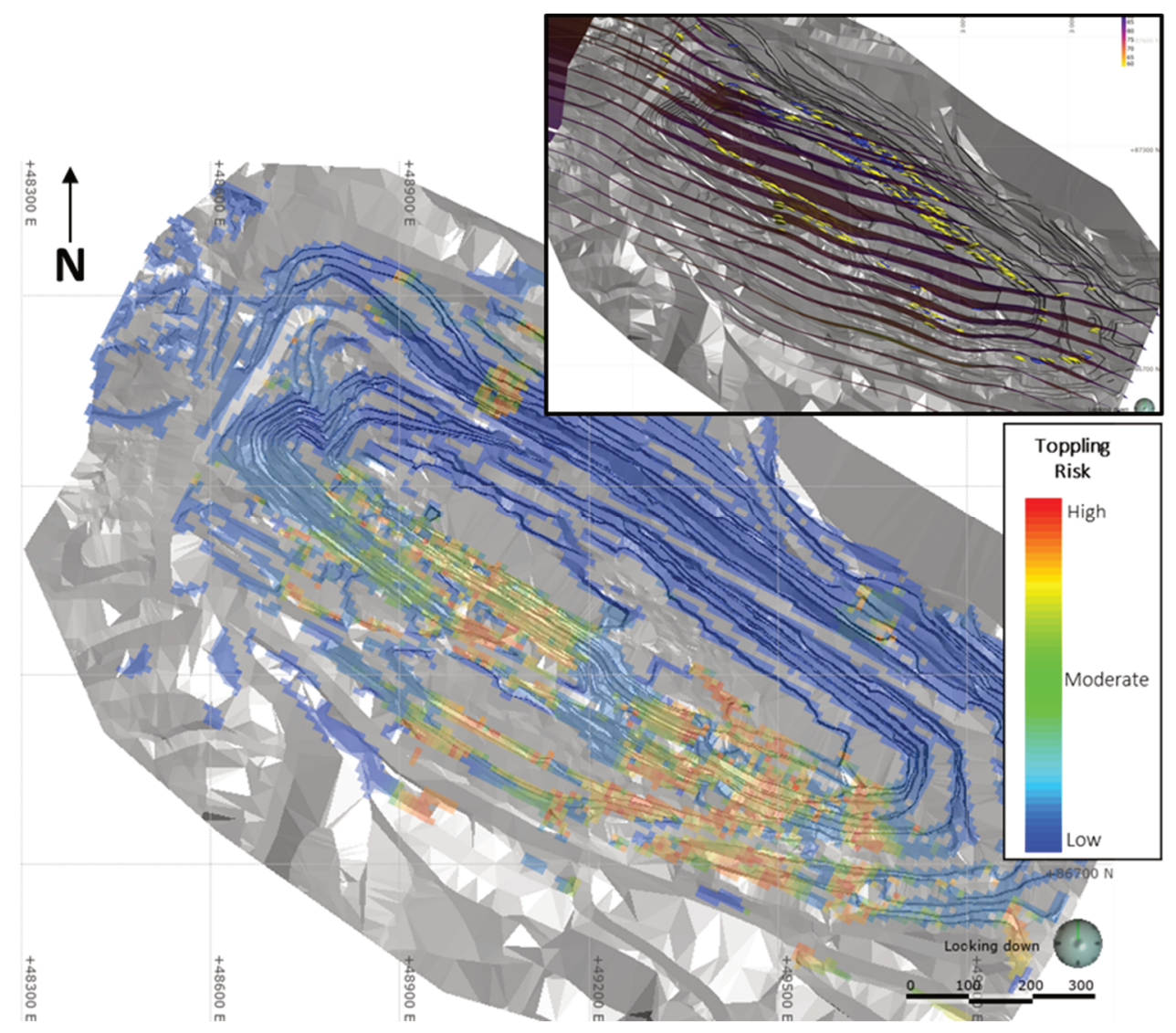

Figure 12 Block model of toppling risk along foliation based on 3D form interpolant of foliation (inset)

\section{Domain characterisation}

Functional slope designs require domains representing. General domaining concepts have been introduced through this paper and require similar lithology, structure geological and/or rock mass conditions. Specifically for antistrophic rock masses, the lateral and vertical domaining as a function of waviness along strike and/or down dip can be supported with data-driven 3D form interpolants. Figure 13 demonstrates a review of the orientations determined by the form interpolant model to evaluate vertical domaining through a deposit.
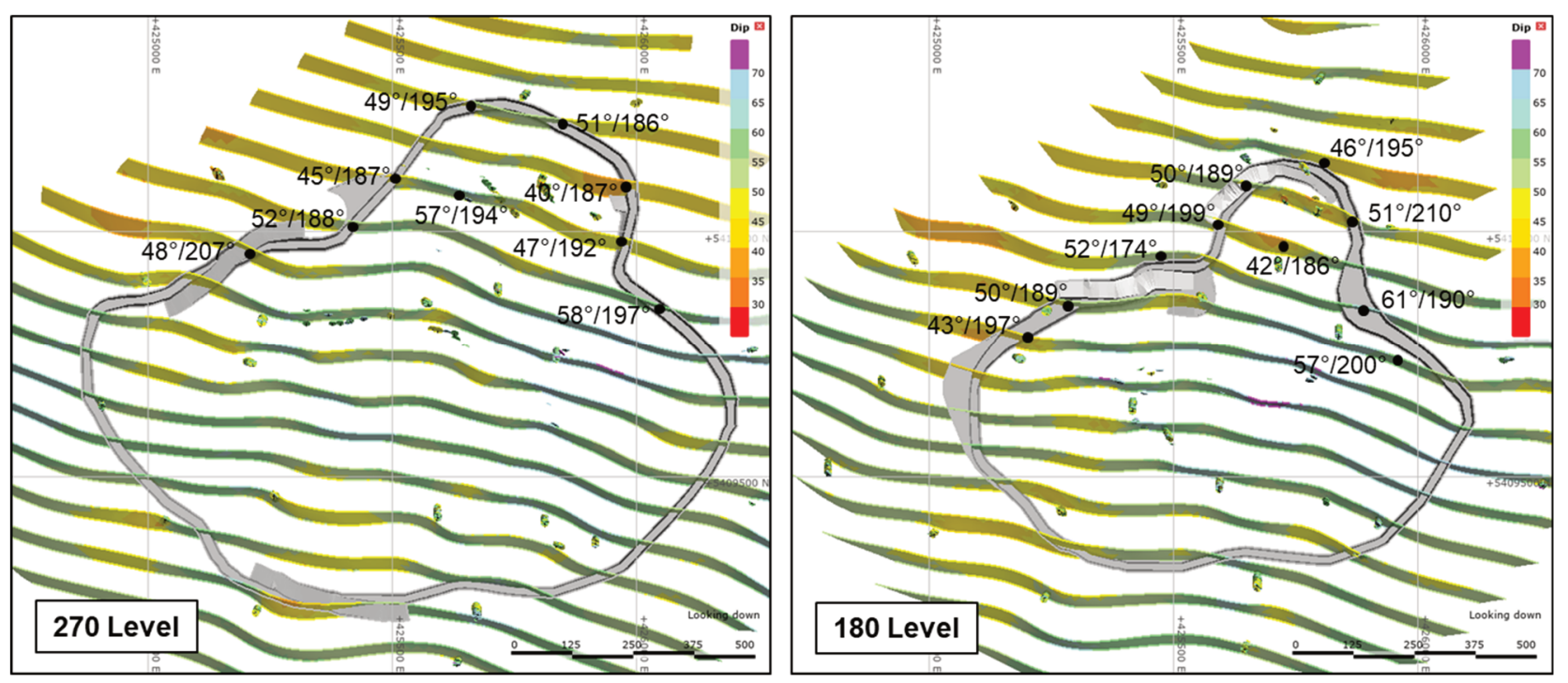

Figure 13 Vertical slices cut through a form interpolant to evaluate orientation variability with depth 


\subsection{Interpretation}

A 3D form interpolant cannot define a slope design alone. The scale and rock mass and shear strengths require characterisation as discussed for the Rosebel case study. Bar \& McQuillan (2018) describes BIF anisotropy in the Pilbara into:

- Bedding scale anisotropy can and should be modelled using a rock mass directional shear strength criterion.

- Banding scale anisotropy that may be analysed as discrete weak bands.

This concept is shown in Figure 4, where at a small enough scale, it is no longer practical to account for foliation variation in a 3D interpolant, and it must therefore be factored into the shear strength inputs that are used during stability analysis.

\subsection{Indicators for shear strength}

Determination of shear strengths for the features within a characterisation domain need to consider the geological setting as described in Section 2. For example, metamorphic rock masses with a high micaceous or chlorite content may more readily form planes of weakness in low stress environments. Aspects that need consideration in shear strength determination include:

- Localised and deposit-scale waviness.

- Weak layering or interbedded units.

- Roughness at varying scales is an important component of the shear strength of discontinuities.

- Infill materials.

- Rock bridging where anisotropic fabric is less pervasive.

As shown in Figure 14, the degree of waviness or large-scale roughness can often be evaluated when looking at the 'spread' of logging data, as described by Thomas et al. 2015. This variability can provide input to the larger scale peak shear strength determination. This reinforces the importance of properly categorising foliation data during the field campaign so that measurements can be confidently included in the 3D form interpolant.

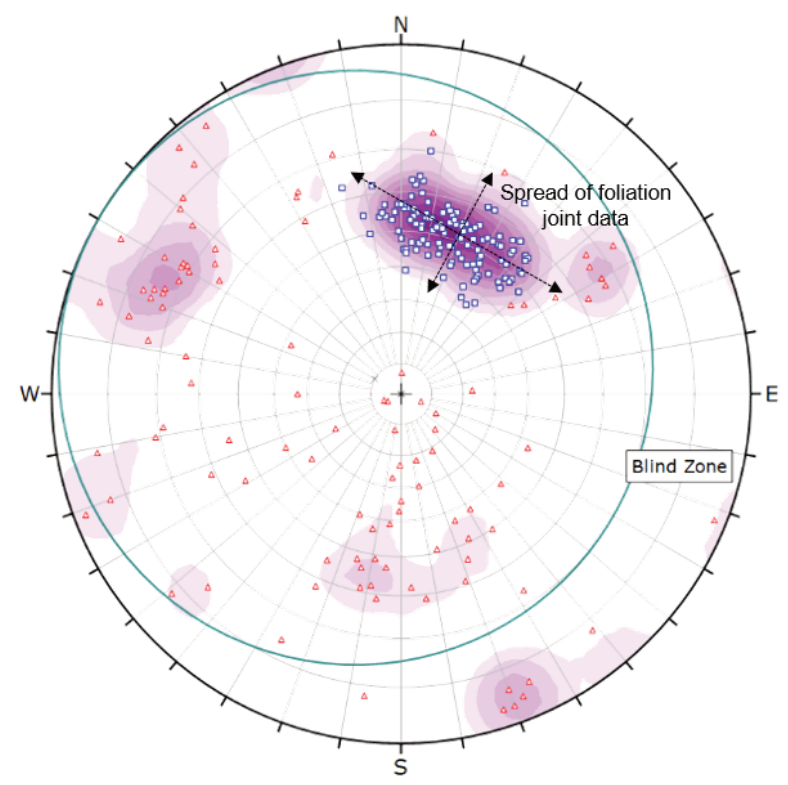

Figure 14 Stereonet of borehole data with foliation-parallel joints shown in blue 


\section{$5 \quad$ Design implications}

A benefit of implicit modelling is the ability to quickly adjust the model based on the collection of new data at the study phase or from the exposed bench faces. These adjustments are essential for developing observational-based designs such as those required where the orientation of dominant foliation structures varies between levels and bench face angles require continual adjustment for optimum performance. In this case, the form interpolant should be reviewed as part of the approval process for bench and wall control blast design.

At the inter-ramp scale, the form interpolant can be used to identify large-scale risks such as undercutting of the pervasive fabric. As shown in Figure 15 (Murphy \& Barnett 2018), anisotropy influence on stability is a fundamental constraint on the expected performance and constraining elements on design.

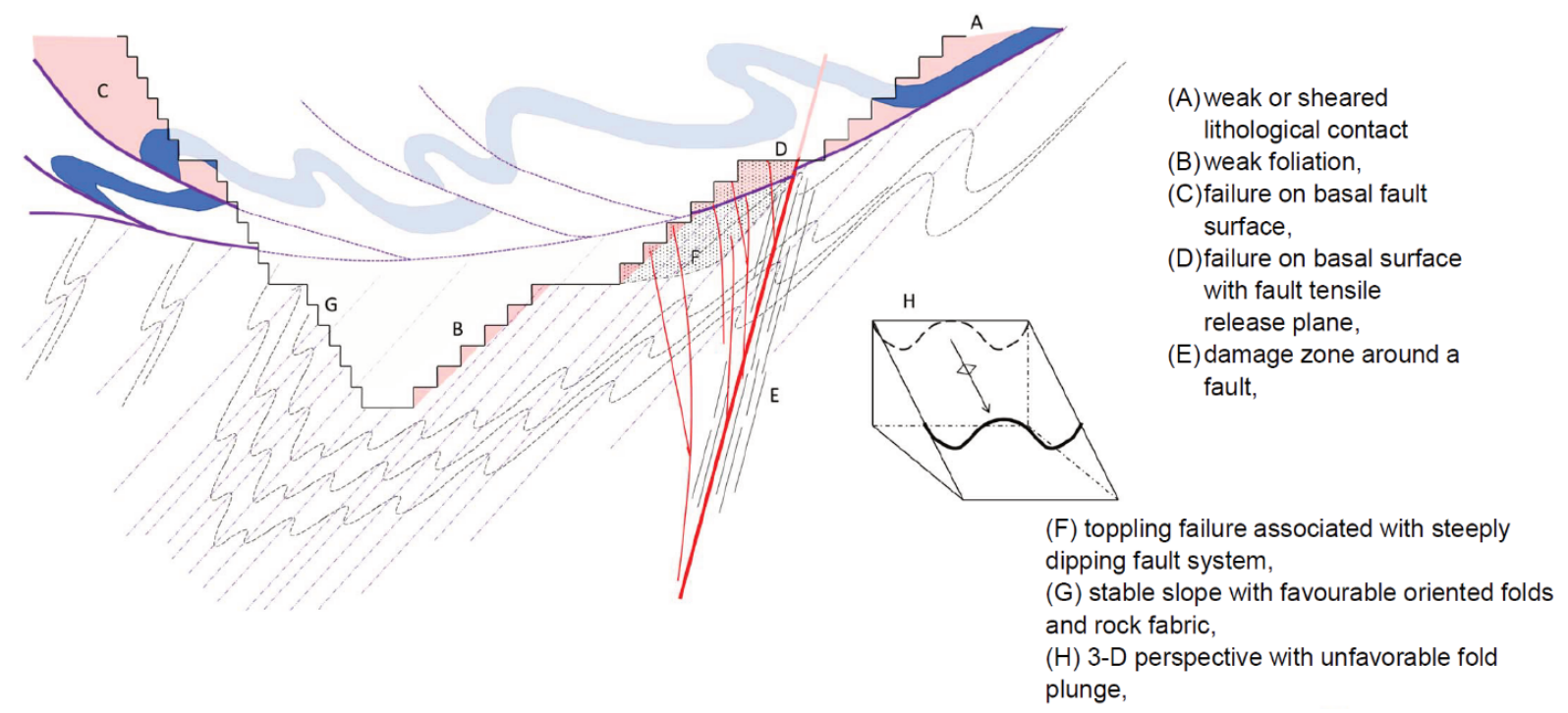

Figure 15 Schematic illustration of typical structural geology influences on open pit stability in orogenically deformed rock mass. Red shading indicates possible sliding or wedge failure (Murphy \& Barnett 2018)

Furthermore, the design of anisotropic rock masses should consider the following points, including the level of conservatisms that may need to be considered in the design work:

- The density of orientation data.

- Presence of waviness in the deposit on a regional scale.

- The larger scale structural model.

- The risk profile of the slope.

- The scale of analysis being undertaken.

\section{Conclusion}

As the use of 3D design tools become more widely practiced in the mining industry, more careful understanding needs to be payed to the influence of anisotropy, and its spatial variability, on pit slope performance. This can ultimately be achieved through the development of a rock mass fabric model based on downhole and surface mapping data, coupled with a sound understanding of the geological setting. Using implicit modelling techniques, this allows for the fabric model to be rapidly updated as new data is collected. This approach can provide a powerful tool during the initial design cycle, as shown at Rainy River, or during a mine's life, as design plans change and updated stability assessments need to be made. 


\section{Acknowledgement}

The authors would like to acknowledge the technical services teams at New Gold's Rainy River Mine and IAMGOLD's Rosebel Gold Mines for the continued support and allowing the information presented in this paper to be published. Also, Anton Bloem of SRK Vancouver for value insight during the paper preparation.

\section{References}

Bar, N \& McQuillan, A 2018, '3D Limit Equilibrium Slope Stability Analysis for Anisotropic and Faulted Rock Masses in Australian Coal and Iron Ore Mines', Proceedings of the 10th Asian Rock Mechanics Symposium, International Society of Rock Mechanics, Singapore, https://www.onepetro.org/download/conference-paper/ISRM-ARMS10-2018-127?id=conference-paper\% 2FISRM-ARMS10-2018-127

Creus, PK, Basson, IJ, Koegelenberg, CK, Ekkerd, J, de Graaf, PJH, Bester, M \& Mokele, T 2019, '3D Fabric Analysis of Venetia Mine, South Africa: Using Structural Measurements and Implicitly-Modelled Surfaces for Improved Pit Slope Design and Risk Management', Journal of African Earth Sciences, vol. 155, pp. 137-150.

Hencher, SR, Lee, SG, Carter, TG \& Richards, LR 2011, 'Sheeting joints: characterisation, shear strength and engineering', Rock Mechanics and Rock Engineering, vol. 44, issue 1, pp. 1-22.

Murphy, B \& Barnett, W 2018, 'Approach to Geotechnical Characterization and Slope Design Data Acquisition Programs In Different Deposit Types', Proceedings of the 2018 International Symposium on Slope Stability in Open Pit Mining and Civil Engineering, Asociacion Nacional de Ingenieros de Minas, Seville, pp. 1315-1329.

Passchier, CW \& Trouw, RAJ 2005, Microtectonics, Springer Science \& Business Media, Berlin.

Sainsbury, D \& Sainsbury B 2013, 'Three-Dimensional Analysis of Pit Slope Stability in Anisotropic Rock Masses', in PM Dight (ed.), Proceedings of the 2013 International Symposium on Slope Stability in Open Pit Mining and Civil Engineering, Australian Centre for Geomechanics, Perth, pp. 683-695, https://doi.org/10.36487/ACG_rep/1308_45_Sainsbury

Seequent 2019, Leapfrog Geo ${ }^{T M}$, version 5.0, computer software, Seequent, Christchurch.

Stead, D \& Wolter, A 2015, 'A Critical Review of Rock Slope Failure Mechanisms: The Importance of Structural Geology', Journal of Structural Geology, vol. 74, pp. 1-23.

The University of the State of New York 2011, Reference Tables for Physical Setting/Earth Science, Albany, New York, http://www.p12.nysed.gov/assessment/reftable/earthscience-rt/esrt2011-engr.pdf

Thomas, RDH, Neilsen, JM, Wilson, HF \& Lamb, P 2015, 'Structural interpretation from Televiewer surveys', in PM Dight (ed.), Proceedings of the Ninth Symposium on Field Measurements in Geomechanics, Australian Centre for Geomechanics, Perth, pp. 729-74.

Zorzi, L, Massironi, M, Surian, N, Genevois, R \& Floris, M 2014, 'How Multiple Foliations may Control Large Gravitational Phenomena: A Case Study from the Cismon Valley, Eastern Alps, Italy', Geomorphology, vol. 207, pp. 149-160. 
